\title{
International climate finance from border carbon cost levelling
}

\author{
Professor Michael Grubb \\ Faculty of Economics, Cambridge University \\ \& Chair, Climate Strategies \\ Outlook Insights paper for Climate Policy journal \\ Special Issue on Climate Finance (ed. Haites et al), Issue 11:3 (2011) \\ Revised text 12 Jan 2011 final 24 Jan
}

Keywords: Climate finance; border adjustments; carbon leakage; climate \& trade

\begin{abstract}
The reality of trying to raise substantial long-term revenues for international climate finance, including the outcome of the High Level Advisory Group on Climate Change Financing, is revealing the need for fresh thinking on finance sources, which takes account of political realities. Particularly after the credit crunch it will be very difficult to raise all the international finance required from sources which have clear national identity and are presently under the control of finance ministries in the OECD countries. This paper argues that the revenue associated with charging for the carbon embodied in the international trade of carbon-intensive commodities is an option with attractive properties. The paper explains this option of WTO-compatible 'border carbon cost leveling', indicates potential revenues from its application to key carbon-intensive commodities, and outlines the potential ethical and political economy attractions of the option.
\end{abstract}

\section{Introduction}

The Copenhagen deal on finance - including its objective to reach US $\$ 100 \mathrm{bn} / \mathrm{yr}$ of international finance by 2020 - was hailed as the key breakthrough of the Copenhagen Accord, codified at Cancun. It could also prove to be the Achilles' Heel of these agreements, and of prospects for a more substantive international action. The massive debt accumulated by most OECD countries over the past decade, greatly amplified by expenditures under the "stimulus packages" designed to prevent collapse of the international financial system, means that the OECD faces a decade of budget cuts and belt-tightening. Securing US\$100 bn/yr through normal public sector channels looks, to say the least, problematic.

Recognising the difficulties, the UN Secretary General's High Level Advisory Group on Climate Change Financing (AGF) considered a range of sources including unconventional sources of international finance. It had a tough time. It seems increasingly implausible that OECD governments will make meaningful, individually binding long-term commitments on the scale required from their domestic budgets alone. The US appeals it is constitutionally impossible to make such commitment. Most national Treasuries are already struggling to cut expenditure. And there is no strong domestic political mandate in OECD countries to provide public funds for climate change actions in developing countries, especially China and India. Even new sources seem problematic, and confined to a narrow set of options, each of which raises varied opposition.

Ideally, new options for international finance would have the following characteristics: 
a) Be outside the scope of existing sources of national finance, and preferably not fall naturally under any specific national jurisdiction, to weaken the potential claim of national Treasuries to have unique control over the revenue;

b) Be visibly connected with climate change, and preferably contribute directly to mitigation of climate change; and

c) Carry mutual incentives that could facilitate all sides agreeing to use it as a funding source

This paper discusses an option which could meet all these criteria, but which received little attention in the AGF: extending carbon pricing systems to include a measure of carbon embodied in carbon-intensive imports, and returning the revenue raised at the border to support low carbon development and/or adaptation in developing countries. The specific proposal considered here is for WTO-compatible 'border carbon cost leveling' in regions that adopt cap-and-trade or equivalent carbon pricing. This would require key carbon-intensive commodities, such as steel and cement, to pay for emissions whether they are produced domestically, or imported. The prime purpose is to prevent carbon-intensive producers moving abroad to avoid carbon costs - 'carbon leakage' - by ensuring that consumers in the ETS regions pay for the carbon irrespective of where these commodities are produced. WTO compatibility is most easily assured by auctioning allowances domestically and setting a fixed requirement for importers to purchase allowances equivalent to the best available technology, to ensure that the measure does not preferentially treat domestic producers. This inevitably raises revenue from importers (as well as domestic producers), and the key proposition is that these revenues should be returned to international funds or to country of production.

\section{Rationales}

The underling proposal is located at the interface of two existing policy debates -- the divergence between production and consumption views of accountability for climate change, and the competitiveness and leakage impacts of developed country mitigation policies.

Many developing country analysts and politicians have stressed that greenhouse gas emissions are driven ultimately by consumption - most notably, affluent western consumption (eg. Sunwal, 2009). The shift in production patterns over the past two decades and the associated rapid growth of international trade has increased the gap between the emissions associated with consumption in OECD countries and the actual emissions in those countries. The "carbon footprint" of OECD countries' consumption in aggregate exceeds their domestic production emissions by about $20 \%$. This is matched by a corresponding debit from developing country emissions. Much of the analysis has concentrated on China, where for example Wang and Watson (2008), in common with some other estimates they cite, estimate that almost a quarter of Chinese emissions arise from the production of goods for export.

These authors note that attribution is in fact complex:

"This has led to calls for consumption-based national emission accounts instead of (or alongside) the production-based accounts ... this is believed to have several advantages ... on the other hand, it may not be entirely fair for countries that produce goods for export - and enjoy the gains from this economic activity - to take no responsibility for the associated emissions .." 
In other words, responsibility between producer and consumer is ambiguous - and a reasonable topic of negotiation

The other debate concerns the impacts on competitiveness of unilateral carbon policies, such as the EU ETS - in particular the risk of carbon leakage if industrial production migrates to escape the carbon policies, with the products being imported instead. The idea that industrialised countries should "protect their industries" through generalised border protection is anathema, but there are two underlying issues that do deserve attention.

First, industrialised countries are taking action to avoid carbon leakage: it is politically impossible for governments to inflict significant economic loss with no environmental gain (or even, a worsened environmental impact), which is what carbon leakage implies. The main action they have taken is to largely exempt major industries from carbon pricing, mostly by giving them emission allowances for free. This is a common feature of all emission trading schemes to date, and the EU now has an extensive list of sectors receiving free allowances for precisely this reason. The sectors so treated, globally, account for most of manufacturing emissions. To start the journey towards deep emission reductions by exempting sectors that account for about a third of global emissions is not a very promising way to solve the climate problem.

The second issue is moral: there is no ethical or reasonable basis to expect the governments trying to charge for carbon emissions, or their consumers, to actively discriminate against their own producers, by paying for carbon on domestically produced goods whilst giving an exemption to imports.

Note that this is a very different perspective from the general argument about "border adjustments" vis-à-vis other countries, that have been suggested by some European political leaders and, more prominently, in early versions of proposed US legislation. These proposals laid the stress on assessing "adequate" action by other countries. The proposition here is entirely non-discriminatory and more modest: for policies that seek, to the extent practical, to level carbon costs between domestic and foreign production.

\section{Specific proposition}

Climate policy can only realistically move forward if both of the above concerns - the role of consumption, and the need to facilitate a level playing field in a world of unequal carbon pricing - are acknowledged and considered. Moreover, although consumption is seen to be a "southern" preoccupation, and carbon leakage is a "northern" concern, they are two sides of the same coin: a consumption-based perspective implies that consumers should pay for the full carbon consequences of their consumption, wherever goods are produced. In short, to move forward on climate policy, we will need to find some middle ground between the production and consumption views of the world, so that the carbon emitted in producing internationally traded goods that are consumed in regions implementing carbon prices, also pays a carbon price. Key questions are how it could be done and what might happen to the revenues?

The question of "how it could be done" is considered by various analysis. One relatively early proposition (Mueller and Sharma, 2005) was that developing countries should levy carbon charges on their exports of carbon-intensive goods. This indeed could be a desirable outcome, but faces the difficulty that producers face the converse 'carbon leakage' problem: 
unless it is done in a fully multilateral way with all producers participating, production would tend to shift to those countries not levying such export charges. It is potentially a goal, but not a starting point, of the likely evolution of border- related measures.

Others consider the options for actions by countries that seek to impose a carbon price. Droege et al. (2009) review the principles and estimate carbon impacts; Monjon and Quirion (2010) look at EU design; Lockwood and Whalley (2008) point to the many parallels with VAT, now adopted by around 130 countries. Khrebtukova (2010) explores and develops the argument that border adjustment is an essential and legitimate part of developing healthy regulatory competition in carbon control. The Carbon Trust (2010) emphasise the need for sector specific treatment, a theme developed in Grubb, Hourcade and Neuhoff (2011) to emphasise that policy should develop incrementally, on the basis of scale, exposure and simplicity.

Any border-related measure, including a requirement to purchase allowances for the emissions associated with the production of a good, would be subject to World Trade Organization (WTO) rules unless explicitly exempt. GATT compatibility can be most simply assured by requiring importers to buy allowances at a fixed rate reflecting the 'best available technology'. For example, EU cement importers would have to buy a fixed number of allowances per tonne upon import, at the level of the best plants in the EU: this ensures that the measure is intrinsically both non-discriminatory, and cannot preferentially treat domestic producers that pay for their actual emissions. The Carbon Trust (2010) study concludes that cement is the simplest sector, whilst the complexities of steel imply that several years would be required to develop a workable scheme, and other commodities might require different approaches due to their indirect (eg. electricity-related) emissions. The BAT approach does have limitations in terms of economic incentives (eg. Ismer and Neuhoff, 2007) but it is much simpler as a starting point than most other proposals.

For exports, the Subsidies and Countervailing Measures (SCM) agreement could allow for carbon charges incurred in domestic production to be reimbursed upon export (Lockwood and Whalley (2008); Droege et al. (2009); Khrebtukova (2010)).

Such approaches are quite distinct from the broader and more political proposals to use border adjustment proposals to discriminate between different countries. Because the focus is on levelling carbon costs between consumption and production at the border, I use the distinct term 'border carbon cost levelling.'

Whilst not the main motivation, such measures would clearly have revenue implications. First and foremost, they would enable domestic regulations like the EU ETS to move towards auctioning, rather than free allocation, raising domestic revenue. In regions still debating options, it would alternately remove one of the most potent arguments against carbon taxation. Import and export adjustments would have different revenue implications, as well as different legal bases. Export carbon cost reimbursements would reduce the net revenue to Treasuries from domestic auctioning, for the sake of ensuring that exports were not placed at an unfair competitive disadvantage. The central argument of this paper is that import levelling would generate revenues that should be made available for developing country climate-related expenditures. 
Given the complexities of negotiating and implementing such a system it is useful to consider scenarios some years hence, say 2020, focused on just the most exposed big sectors. The Carbon Trust (2010) study proposes starting with the simplest and most carbon-intensive commodity, cement, and moving to other big direct emitters, notably steel, not later than 2020. Cement and Steel production activities each account for about $6 \%$ of global CO2 emissions (thus far exceeding the emissions from international bunker fuels, for example). As shown in Figure 1, together they account for about a third of total global industrial CO2 emissions.

Moreover emissions from cement manufacturing, and flat steel production from blast furnaces (which accounts for most steel trade), are almost entirely direct (as opposed to electricity-related)indeed these two sectors alone account for more than half of all industrial direct emissions. This hugely simplifies the process: their 'border benchmark' rate can just address direct emissions and ignore any electricity-related component (which is equivalent to a 'best available technology' assumption of electricity from renewables or nuclear). ${ }^{1}$

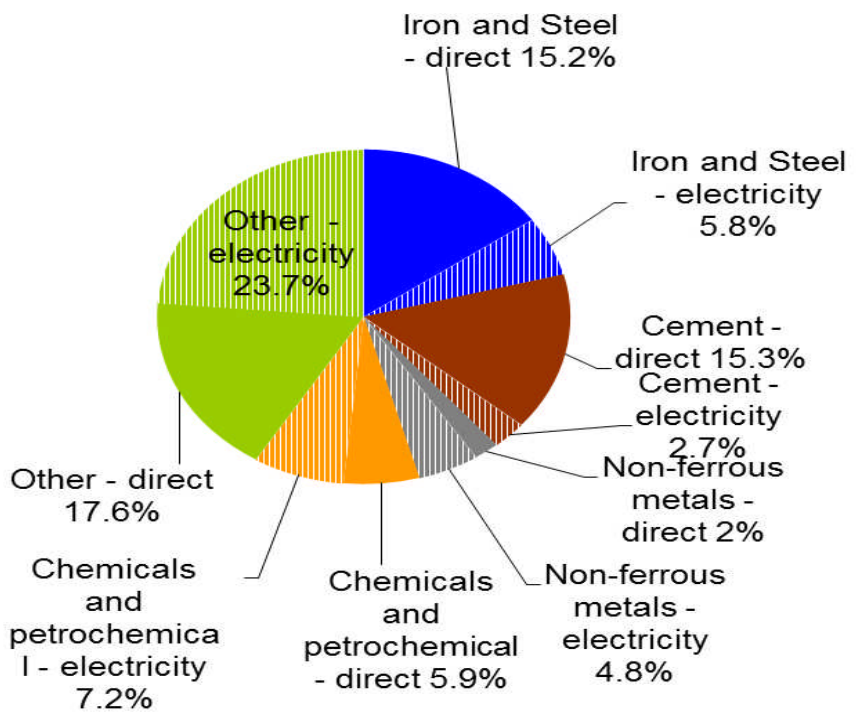

INSERT Figure 1: Global CO2 emissions by industrial sector, 2005

Source: IEA (energy) and ESDS (process emissions), as compiled in Grubb, Hourcade and Neuhoff (2011), Chapter 4.

Table 1 examines possible revenue implications associated with just these two sectors paying for the carbon emitted domestically, and in the production of imported goods. It presents numbers based on recent data for just two illustrative regions - Europe (the EU ETS region), and OECD. Estimates are shown for carbon prices of $€ 15 / \mathrm{tCO} 2$ and $€ 30 / \mathrm{tCO} 2$, roughly the range seen to date in the EU ETS and within range of 2020 projections. For simplicity in the Table, production and imports are converted at approximately the "best available technology"

\footnotetext{
${ }^{1}$ Indirect (electricity-related) emissions add hugely to the complexity of any border-related measures, because they require both measuring emissions at source, and assigning electricity producer emissions to specific industrial consumers, which is fraught with difficulty.
} 
emission rate, in part to allow for continuing improvements in performance under the influence of carbon pricing, and comparability with a fixed rate for border levelling (current average performance is far short of that used in the table).

Table 1. Indicative carbon revenues from cement and steel production and trade

Volume (Mt)[1]

EU

OECD

Carbon emissions benchmarked @ 0.7 tCO2/tonne

cement

Production* Imports*

Production*

Imports*

$\begin{array}{llll}250 & 35 & 560 & 70\end{array}$

Approx revenue if paid at $€ 15 / \mathrm{tCO}$ *

175

24.5

392

49

Approx revenue if paid at $€ 30 / \mathrm{tCO} 2$ *

2625

367.5

5880

735

5250

735

11760

1470

Volume (Mt)[2]

120

70

250

130

Carbon emissions benchmarked @ $1.8 \mathrm{tCO} 2 /$ tonne steel

216

126

450

Approx revenue if paid at $€ 15 / \mathrm{tCO}$ *

3240

1890

6750

3510

Approx revenue if paid at $€ 30 / t C O 2 *$

6480

13500

7020

Notes: [1] Cement including clinker imports, roughly at 2006-7 levels. Data from G.Cook (2009), Climate change and the cement industry, www.climatestrategies.org and the Cement Sustainability Initiative, www.wbcsdcement.org.

[2] Blast furnace (production), gross commodity steel European imports into EU ETS \& linked countries, roughly as at 2007 levels but with modest increase over time reflecting trends for OECD (source: World Steel Association, World Steel in Figures, 2009).

* Note that both production and import volumes would be affected by carbon pricing, for some estimates see the calculations in Droege et al (2008); given instrinsic projection uncertainties, this is ignored in the table which aims just to give a sense of overall order-of-magnitudes. Note also that reimbursement of carbon costs upon export would offset against the production revenues. The EU and OECD export virtually no cement, but the EU is a significant steel exporter. However these are mostly to other OECD countries, have been quite volatile, and are expected to decline, and since the focus of this paper is upon international finance, no attempt at such adjustment is made in this paper.

If domestic EU producers had to pay $€ 15-30 / \mathrm{tCO} 2$ for all their emissions, the cement and steel sectors combined would have to pay $€ 5-10 \mathrm{bn}$ annually in domestic auctions, with steel the slightly larger component. Cement trade is relatively small, and the revenues associated with the carbon embodied in imports to Europe - even if these were at roughly the highest level seen in recent years (a volume driven partly by the construction boom in southern Europe) - would be under $€ 0.5-1 \mathrm{bn} / \mathrm{yr}$. Steel is another matter, with a much higher trade intensity already, and expected to grow further. If Europe imported $70 \mathrm{Mt}$ of steel, the revenue raised at the border would be around $€ 2-4 \mathrm{bn} / \mathrm{yr}$ at this price range.

If a wider area such as the OECD as a whole were engaged in carbon pricing, each \$/CO2 of carbon price would raise about $\$ 1 \mathrm{bn} / \mathrm{yr}$ from cement and steel combined: total OECD auction revenues would be $€ 15-30 \mathrm{bn} / \mathrm{yr}$ for the range $€ 15-30 / \mathrm{tCO} 2$, though the higher end of this range seems less plausible across the OECD by 2020. With cement trade static and some growth of steel imports, the revenues associated with border levelling at a carbon price of $€ 15 / \mathrm{tCO} 2$ could be around $€ 3.5 \mathrm{bn} / \mathrm{yr}$ - maybe about US $\$ 5 \mathrm{bn}$, primarily from steel.

Obviously, these estimates are rough and depend on the assumptions, but they are sufficient to give a sense of scale. Extending the coverage to other products would, of course, increase 
the revenue accordingly. In the context of the US\$100bn/yr sought, making the revenues from border levelling available to international climate expenditures would be a modest but after allowing for exchange rates and other sectors - far from a trivial contribution.

\section{Border levelling as an international resource}

It is of course simplistic just to identify a source of revenue and assume it could be available for international purposes. In the international arena, policy has more to do with the economic interests of individual countries, and finding approaches with mutual benefit. Why might countries agree?

Countries pursuing emission reductions through cap-and-trade (or other carbon pricing) have two reasons to consider the option. Today, even regions making strenuous efforts to price carbon are having to give almost all the energy-intensive traded sectors receive free emission allowances: the fear of 'carbon leakage' is too potent and pervasive to ignore. Border levelling would enable them reduce or eliminate free allocation to internationally traded sectors. Even if they give up claim to the revenues from border levelling, there is a huge leverage incentive: in cement for example, for each Euro paid for imports, EU countries would raise around ten times as much by being able to auction allowances to domestic cement producers as well, without fear of carbon leakage.

The other reason is that the same fears impede strengthening the system. The EU ETS rules for Phase III allow free allowances in proportion to a sector's share of the overall EU cap. Moving from a $20 \%$ to $30 \%$ emission reduction by 2020 would both reduce these free allowances and drive up the carbon price, and the resulting increased risk of carbon leakage is a major reason why the EU is politically unable to strengthen its position. The lack of border levelling means that ETS regions both forego revenues (associated with domestic auctioning) and are trapped into a weaker climate change policy than would otherwise be possible.

The underlying research demonstrates that the simplest form of border levelling - a requirement for importers to purchase allowances at a fixed 'best available technology' rate per tonne of product - would be WTO compatible. In theory, this suggests that countries could implement this basic measure unilaterally. For multiple reasons, it would however be desirable to gain international acceptance.

Is this likely? Other countries would benefit from the ability of these countries to strengthen their climate action: no region benefits from ETS countries having to .

exempt large swathes of industrial production from paying a carbon price. They need only acknowledge the truth that no politician is going to impose a carbon price on a sector which can make a politically credible threat to migrate, to see the potential benefits of border levelling.

However this may carry limited weight in international trade and financial circles. As indicated, the revenues associated with border levelling would not only be a new source of revenue, but one specifically associated with international exchanges. As noted in the quote above, it is a matter of open debate who is really responsible for the associated emissions the producer or the consumer. This introduces an additional element to gaining international acceptance, indeed countries could negotiate not just about the revenues, but the underlying 
attribution of associated emissions between producer and consumer, addressing a point made by key developing countries including China for many recent years.

Of course, the first preference of key developing country producers might be to capture the revenues directly themselves, through a charge on their exports (Mueller and Sharma, 2005). But as noted attempting this unilaterally would put their own producers at a disadvantage in export markets, vis-à-vis other producers. The best approach again is to negotiate border levelling - including the use of revenues - at a multilateral level. This ultimately is why all parties have an incentive to consider the option seriously.

Who really pays?

A key question will be who really pays? Most directly, the answer is the consumer in the carbon pricing region, who now cannot escape any domestically-imposed carbon cost through imports. Of course the full effects can be more complex.

As compared to the default case (carbon intensive production escaping carbon costs), a carbon price on a commodity consumed in any given region will reduce demand. Assuming that domestic and 'embodied' carbon is charged at the same rate - most simply by requiring importers to purchase emission allowances from the same market as domestic production their relative costs (including carbon) will influence the impact. If the border levelling is a fixed benchmark based on 'best available technology', then imports may gain a slight relative advantage, to the extent that domestic production on average falls short of the best technology.

Economic principles related to the elasticity (price-sensitivity) of demand dictate the exact response, but in general the demand for basic commodities is not very price-sensitive, and producers pass the most of the costs through. The net result is that the final consumer would indeed pay the great majority of costs associated with border levelling. Moreover, a significant proportion of revenues would arise from trade flows between Annex I Parties. If the money is used for expenditure in developing countries, therefore, it easily satisfies the basic principle behind 'common but differentiated' responsibilities.

Moreover, any direct effects would to a degree be offset by equilibrating effects in the rest of the economy. A simple equilibrium model by Whalley (2010) suggests that the net effect of a US $\$ 25$ border levelling charge by the EU, would be an impact on China of around $0.001 \%$ of GDP even if none of the money came back to China - equivalent to less than one foregone hour of Chinese economic growth.

Revenue collection and disbursement

Border levelling could be implemented in various ways. The crudest would be for Customs and Excise in ETS countries to require importers hold domestic emission allowances (eg. EU ETS allowances) upon import. 
Alternatively, requiring importers to hold CDM Certified Emission Allowances (excluded from the kind of 'supplementarity' constraints the EU currently imposes) would be the simplest way of ensuring the revenue is recycled back to developing country projects in a neutral way. At the opposite extreme, money raised could be returned directly to the country of export, but perhaps for example governed to ensure the money is spent on NAMAs or other form of recognised low carbon development plans.

If the finance were to be placed firmly in the context of the new fund proposed under the Copenhagen Accord, other avenues might need to be considered. These could include, for example, negotiating a special form of allowance to be auctioned under the authority of the $\mathrm{COP}$, which all signatories would agree to recognise as qualifying for border levelling compliance. This would have the advantage - from a multilateral and trade perspective - of placing the terms of auctions (for example, the 'benchmark' level of assumed best practice emissions) in the multilateral arena, further insulating the process from protectionist pressures. The decision on such terms would presumably have to be decided jointly between the COP and WTO.

\section{Conclusions}

Border levelling has two major benefits. It can facilitate stronger action by countries pricing carbon, and can raise revenue that is intrinsically well suited as a source for international expenditures (with revenues that, as illustrated in this paper, are far from trivial even from just two industrial commodities). The world is currently struggling on both fronts.

Developed countries need to abandon rhetoric about using trade protection to force other countries to do more, and focus instead on legitimate goals associated with ensuring that their own policies do not create unreasonable disadvantage. Within this they need to accept shared responsibility for emissions associated with their consumption patterns, and pursue the obvious consequence that imports should also pay for their embodied emissions.

Developing countries do not benefit in any way from the current situation in which countries adopting carbon prices have to exempt large swathes of industrial production from paying it, for fear of carbon leakage. They need only acknowledge the truth that no politician is going to impose a carbon price on a sector which can make a politically credible threat to migrate to see the potential benefits of border levelling; but they could reasonably insist that solutions be pursued in a multilateral setting, with revenues devoted to international climate finance.

If industrialised countries are keen to price carbon properly, and if developing countries are serious about a more consumption-oriented approach - then it makes sense that border levelling and the use of associated revenues should be on the table of international negotiations. It is time to shake off prejudices and rhetoric, and take a close look at the potential mutual benefits.

\section{References}

Carbon Trust (2010), Tackling carbon leakage: sector-specific solutions in a world of unequal carbon prices, Feb 2010. www.carbontrust.co.uk. The present author was Chief Economist at the Carbon Trust at the time, and lead author of the report; and also Chair of Climate Strategies, the organisation that commissioned the underlying academic analysis led by S.Droege et al. (2009). 
Droege S. et al. (2009), Tackling leakage in a world of unequal carbon prices, Climate Strategies synthesis report, www.climatestrategies.org

Ismer R. \& K. Neuhoff (2007), Border Tax Adjustments: A Feasible Way to Address Nonparticipation in Emission Trading, Eur. J. L \& Econ. Vol. 24:137

Monjon S. and P. Quirion (2010), 'How to design a border adjustment system for the European Union Emissions Trading System?', Energy Policy, doi:10.1016/j.enpol.2010.05.005

Mueller B. and A.Sharma (2005), 'Trade tactic could unlock climate negotiations', SciDev.net, 23 June 2005, http://www.scidev.net/Opinions/index.cfm? fuseaction $=$ readOpinions\&itemid $=399 \&$ language $=1$

Grubb M., J.C.Hourcade and K.Neuhoff (forthcoming 2011), The carbon connection: climate change solutions for our energy, economic and geopolitical challenges, Earthscan, London.

Lockwood B. and Whalley J (2008), Carbon motivated border tax adjustments: old wine in green bottles? NBER working paper 14025, www.nber/org/papers/w14205.

Khrebtukova, A (2010), 'Using national border climate adjustment schemes to facilitate global greenhouse gas management in industrial production', Wash \& Lee J. Energy Climate and Env't 107 (2010)

Sunwal M. (2009), Reflection on the climate negotiations: a southern perspective, Climate Policy 9:3, 330-333

Wang T. and J. Watson (2008), China's carbon emissions in international trade: implications for post-2012 policy, Climate Policy, 577-587.

Whalley J. (2010), 'The impact of carbon motivated border tax adjustments', presentation to seminar at Cambridge University, 28 Aug 2010. 